\title{
四得品 \\ Female genital mutilation in children presenting to a London safeguarding clinic: a case series
}

Editor's choice Scan to access mor free content

${ }^{1}$ University College Hospital, London, UK

${ }^{2}$ Department of Paediatrics, The Whittington Hospital, London, UK

\section{Correspondence to} Dr Deborah Hodes, Department of Paediatrics, University College Hospital, 250 Euston Road, London NW1 2PG, UK; deborah.hodes@nhs.net

Received 16 January 2015 Revised 28 April 2015 Accepted 18 May 2015 Published Online First 27 July 2015

\section{SLinked}

- http://dx.doi.org/10.1136/ archdischild-2014-307234 - http://dx.doi.org/10.1136/ archdischild-2015-308644

\section{CrossMark}

\section{To cite: Hodes $D$,}

Armitage A, Robinson K,

et al. Arch Dis Child

2016;101:212-216.

\author{
Deborah Hodes, ${ }^{1}$ Alice Armitage, ${ }^{1}$ Kerry Robinson, ${ }^{2}$ Sarah M Creighton ${ }^{1}$
}

ABSTRACT

Objective To describe the presentation and management of children referred with suspected female genital mutilation (FGM) to a UK safeguarding clinic.

Design and setting Case series of all children under 18 years of age referred with suspected FGM between June 2006 and May 2014.

Main outcome measures These include indication for referral, demographic data, circumstances of FGM, medical symptoms, type of FGM, investigations and short-term outcome.

Results Of the 47 girls referred, 27 (57\%) had confirmed FGM. According to the WHO classification of genital findings, FGM type 1 was found in 2 girls, type 2 in 8 girls and type 4 in 11 girls. No type 3 FGM was seen. The circumstances of FGM were known in 17 cases, of which $12(71 \%)$ were performed by a health professional or in a medical setting (medicalisation). Ten cases were potentially illegal, yet despite police involvement there have been no prosecutions.

Conclusions This study is an important snapshot of FGM within the UK paediatric population. The most frequent genital finding was type 4 FGM with no tissue damage or minimal scarring. FGM was performed at a young age, with $15 \%$ reported under the age of 1 year. The study also demonstrated significant medicalisation of FGM, which matches recent trends in international data. Type 4 FGM performed in infancy is easily missed on examination and so vigilance in assessing children with suspected FGM is essential.

\section{INTRODUCTION}

Female genital mutilation (FGM) is gender-based violence against women and girls, ${ }^{1}$ is a violation of the rights of the child and is child abuse. ${ }^{2}$ The WHO defines FGM as 'all procedures that involve partial or total removal of the external female genitalia, or other injury to the female genital organs for non-medical reasons'. ${ }^{3}$ An estimated 125 million females worldwide have undergone $\mathrm{FGM}^{4}$ but data are lacking on incidence and prevalence in the UK. However, a recent study in 2011 estimated that over 137000 adult women with a further 70000 girls under the age of 15 have either had or are at risk of FGM in England and Wales. ${ }^{5}$ UK frontline professionals have little knowledge of the characteristics of referral, presentation and examination findings, or optimum management. ${ }^{6}$

FGM has been illegal in the UK since 1985 and in 2003 it became illegal to take a child abroad for FGM. As yet there have been no successful prosecutions in the UK. Despite FGM being a practice almost uniformly carried out in childhood, the medical literature has focused on the obstetric and gynaecological impact on adults rather than the

\section{What is already known on this topic?}

- 125 million women and girls worldwide have had female genital mutilation (FGM).

- There have been no successful prosecutions for FGM in the UK.

- There is no paediatric UK literature on FGM.

\section{What this study adds?}

- The characteristics of female genital mutilation (FGM) presentations in childhood, including reasons for referral, circumstances of FGM, examination findings and short-term outcomes, are described.

- Type 4 FGM includes pricking and nicking and may be difficult to detect.

- A normal examination does not exclude the possibility that FGM has taken place.

paediatric issues. This study describes the presentation, management and outcome of FGM in a tertiary paediatric clinic cohort.

\section{METHODS}

The local Research Ethics Committee approved the study as an audit providing all patient identifiable information was removed prior to analysis and publication.

This was a retrospective study of the case notes and clinic letters on all suspected FGM cases referred to a tertiary safeguarding clinic in an inner London teaching hospital from June 2006 to May 2014. Details of referral, history, examination findings and short-term outcome were recorded.

The lead consultant (DH), who has experience in child maltreatment including child sex abuse, saw all children in an age-appropriate out-patient setting with play specialist support. With written consent, the patient was examined using a colposcope for magnification and photo-documentation. The WHO classification was used to describe the genital findings (box 1, figure 1). Following the consultation, a full explanation was given to the parent/s, child (if age allowed), social worker and police if present. Local child protection guidelines were followed, with relevant reports provided for social care personnel and witness statements taken when requested. 


\section{Box 1 WHO classification of female genital mutilation}

Type 1: Clitoridectomy: partial or total removal of the clitoris (a small sensitive and erectile part of the female genitals) and, in rare cases, removal of the prepuce only (the fold of skin surrounding the clitoris).

Type 2: Excision: partial or total removal of the clitoris and labia minora with or without removal of the labia majora (the labia are 'the lips' that surround the vagina).

Type 3: Infibulation: narrowing of the vaginal opening through the creation of a covering seal. The seal is formed by cutting and repositioning the labia minora or majora with or without removal of the clitoris.

Type 4: Other: all other harmful procedures to the genitals for non-medical reasons, for example, pricking, piercing, incision, scraping and cauterising the genital area.

\section{RESULTS}

During the study period, 47 patients were referred with suspected FGM, with the number of referrals rising sharply after the start of 2013 (figure 2). Forty-one of these patients were examined; the six who refused either gave a history of having had FGM and/or their sibling had been examined and was found to have FGM. Twenty-seven children (57\%) were confirmed to have had FGM based on examination findings and/or the testimony of the child or their parent. In the remaining 20 , there was no history from the child or the parent with whom they were living and genital findings were normal on examination. These girls were reassured and discharged from the clinic after appropriate discussion. Numbers are too small for analysis, but there was no obvious difference between the group of children who were found to have FGM and the group who were not. Routes of referral included being a relative of an index case (12), other child protection concerns (11), school concerns (8), family dispute (7) and contact with medical staff for another reason (5); several cases fell into more than one of these categories.

Eighteen (67\%) of the girls in whom FGM was confirmed were from Somalia. In eight girls, the country where FGM was performed was different from the country of origin (figure 3). No cases of FGM were confirmed to have been performed in the UK. The majority of girls were under the age of 10 when FGM was performed, with four of the $27(15 \%)$ under 1 year of age (figure 4). In 10 (37\%) of the 27 cases, details of the circumstances of FGM were not given or not known by the parent. In the remaining 17 cases, the person who performed FGM was described as a 'doctor' in six cases (35\%), a 'circumciser' in seven cases (41\%) or not described in the remaining four cases. Twelve (71\%) of 17 descriptions mentioned an additional medical feature (anaesthetic creams, 'antibiotics', 'injections' or performed in a medical setting).

Of the 27 confirmed to have had FGM, eight (30\%) reported one or more medical symptoms, including pain (2), bleeding (2), tenderness (2), dysuria (2), nocturnal enuresis (3), adhesions (2), post-traumatic stress symptoms (2), recurrent urinary tract infection (UTI) (1) and slow urinary stream (1). Tests for bloodborne viruses were all negative in this series.

Twenty-one (78\%) of the 27 children confirmed with FGM agreed to be examined. The number of girls with each type of FGM according to the WHO classification is given in figure 5 . Clinically, many of the examination findings fell between WHO classification types. Although WHO type 3 (infibulation) was not documented in this series, in three patients there was
Type 1 FGM

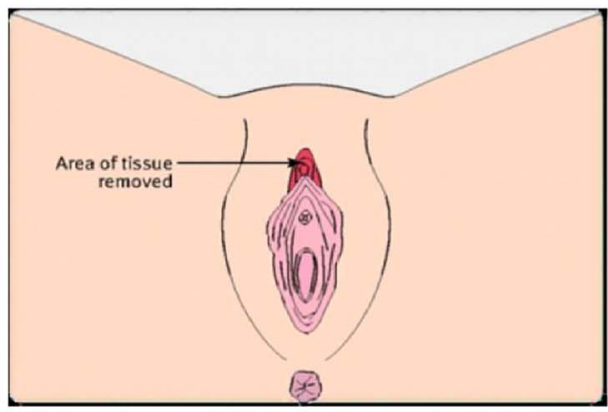

Type 3 FGM

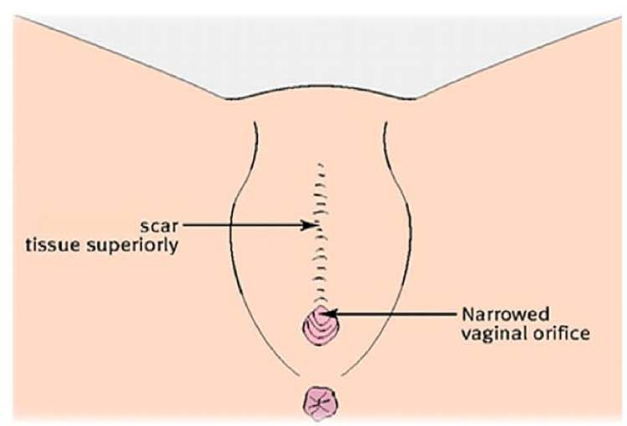

Type 2 FGM

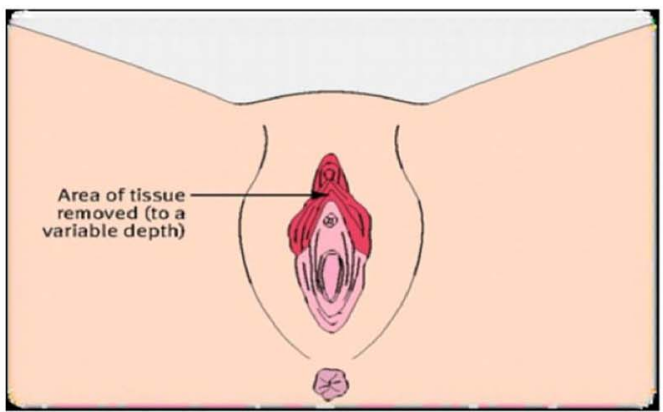

Type 4 FGM

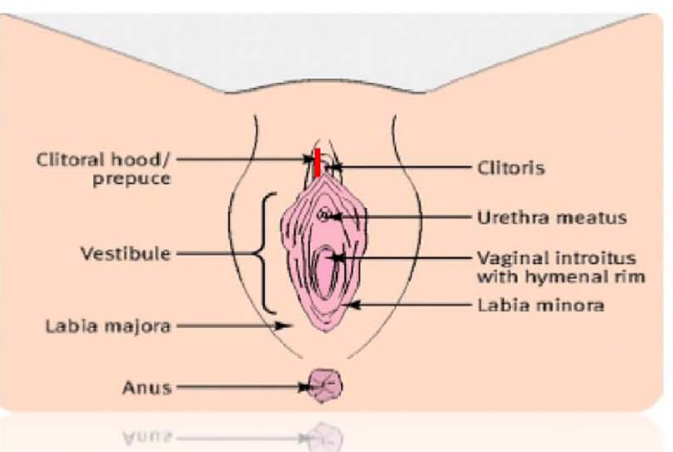

Figure 1 WHO classification of female genital mutilation. 


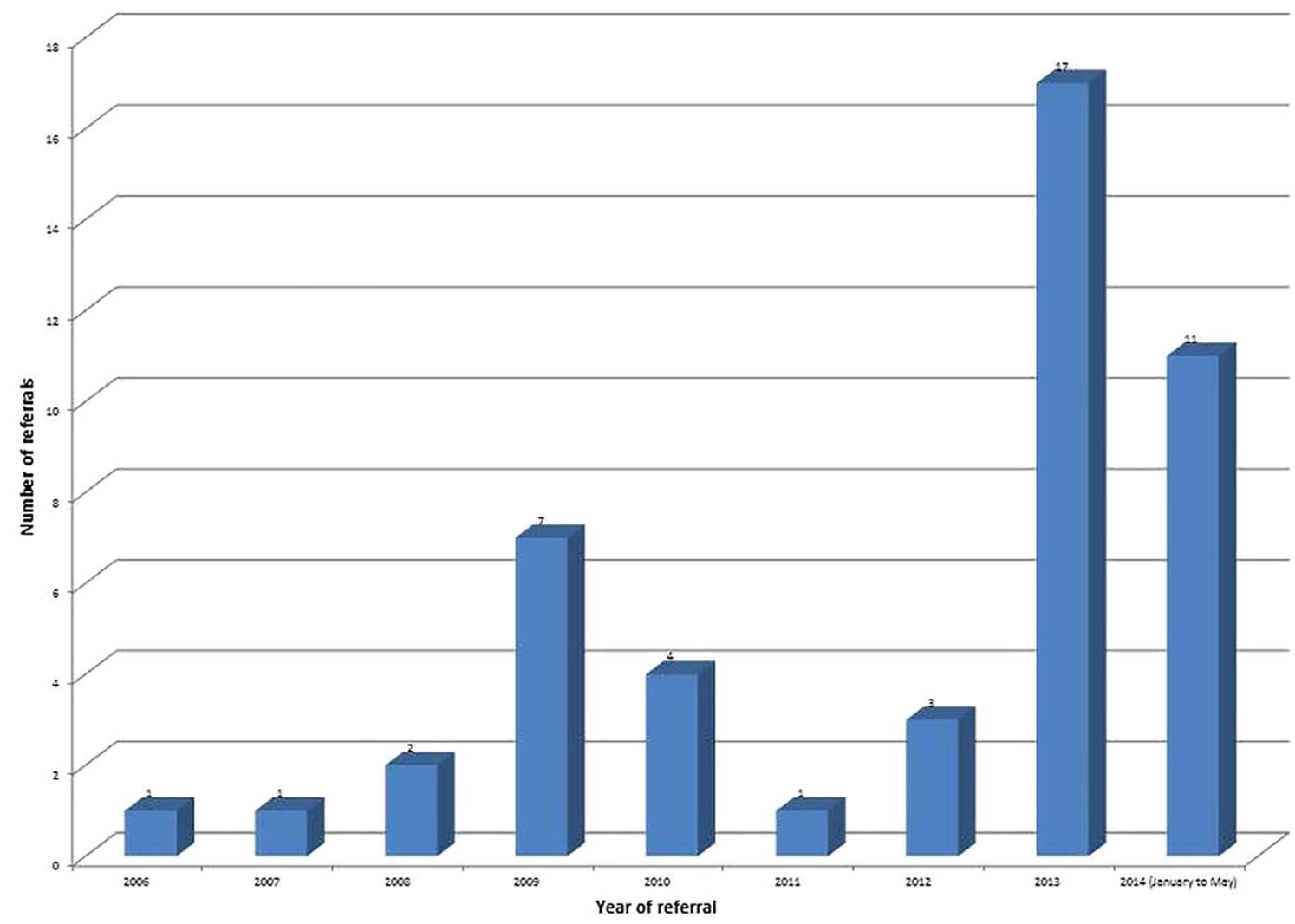

Figure 2 Suspected female genital mutilation referrals by year.

evidence of adhesion/sewing together of the anterior portion of the labia minora (between WHO type $2 \mathrm{~b}$ and type 3 ). Of the 11 patients diagnosed with type 4 FGM, six had evidence of FGM on genital examination and five had FGM confirmed on testimony alone (ie, they had a normal genital appearance with no physical evidence of scarring). These latter children are likely to have undergone genital pricking or nicking, which is classified as type 4 FGM by the WHO.

All cases of confirmed FGM and children considered at risk of FGM were discussed with their social worker. Social care workers conducted further investigation in nine cases and initial strategy meetings were held for four patients, after which the cases were closed. Due to ongoing investigations and confidentiality issues, it is not possible to give details of all cases.

Of the 27 patients with confirmed FGM, three had been taken out of the country to have FGM performed before 2003 (ie, before this became illegal) and 14 had had FGM prior to coming to the UK (ie, before becoming British citizens). In 10 cases the circumstances were either identified or suspected to be illegal and were known to the police. Several cases were considered for prosecution but barriers included insufficient evidence and unclear perpetrators, particularly when FGM had allegedly taken place outside the UK. At least one case was dropped when the child in question declined to testify in court. Some investigations are ongoing.
Figure 3 Country of origin and country of female genital mutilation.

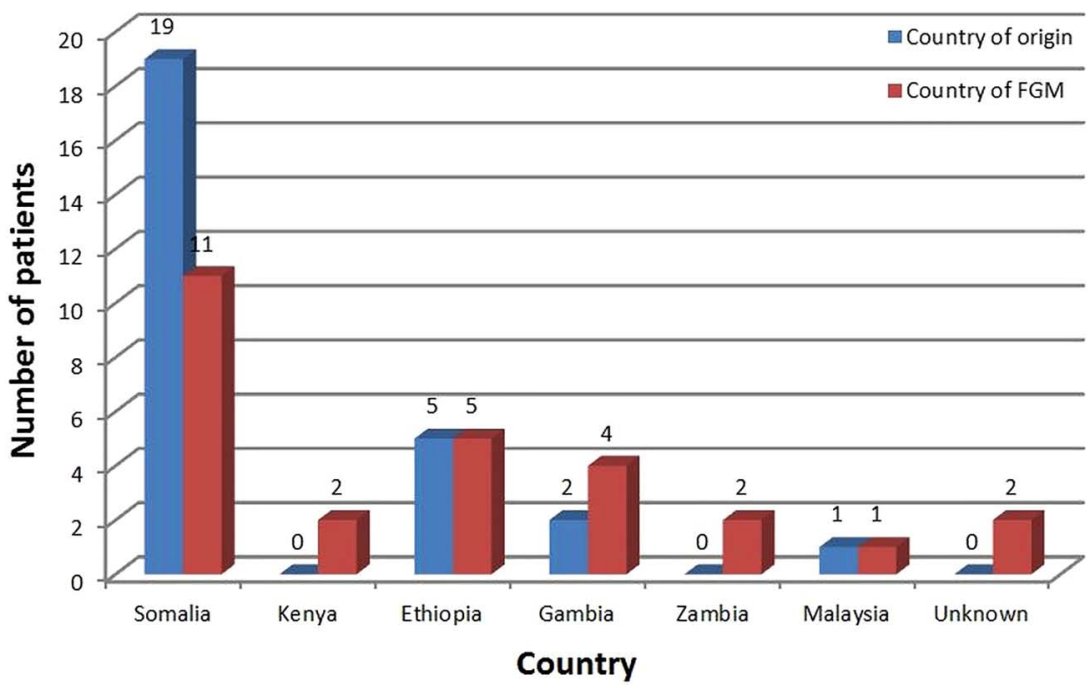

Hodes D, et al. Arch Dis Child 2016;101:212-216. doi:10.1136/archdischild-2015-308243 
Figure 4 Age of patient when female genital mutilation was performed.

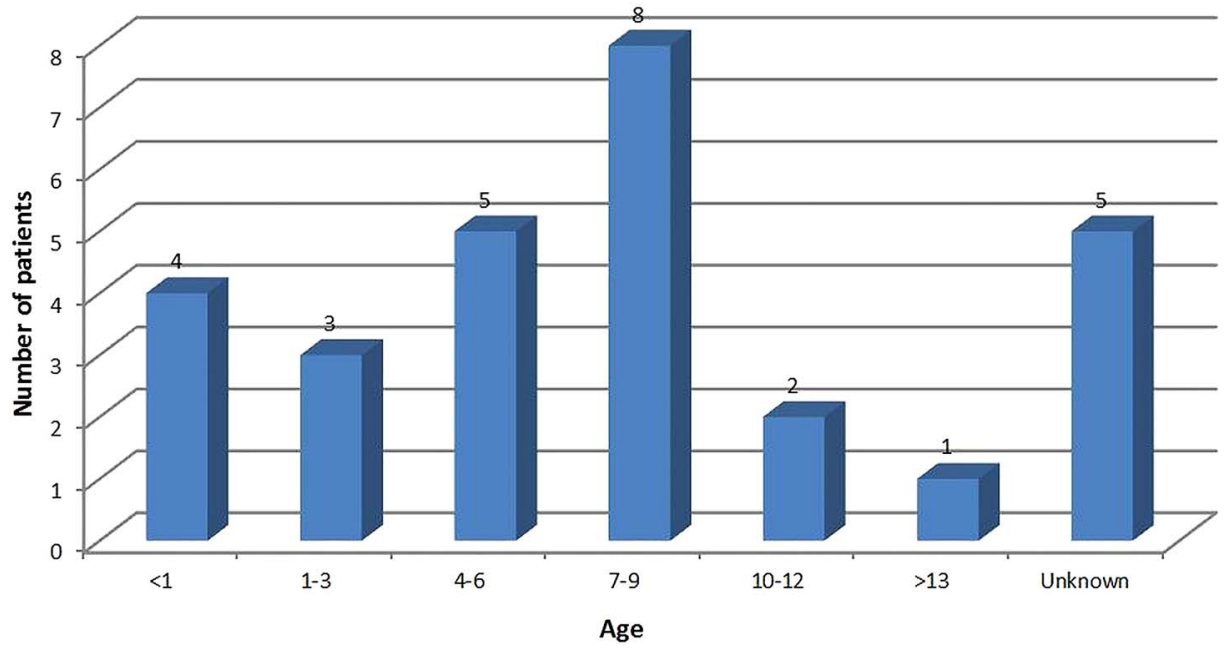

\section{DISCUSSION}

This is the first study to report on FGM in children presenting to healthcare services in the developed world. Given the nature of the practice of FGM, this study can only capture a tiny sample of the FGM within the UK paediatric population. However, it provides a valuable snapshot of the UK situation and highlights crucial issues in detection and safeguarding. The discrepancy between the large numbers of estimated paediatric FGM cases and the numbers of actual documented cases has several possible explanations. There may be a real reduction in the number of procedures, children may have FGM abroad and only return when well, or there may be a trend towards WHO type 4 which is more difficult to detect as illustrated in this study.

The purpose of this case series is to add to paediatric and UK-specific knowledge. However, the three key findings in this series reflect international trends ${ }^{4}$ and are: (i) a move towards type 4 FGM with less tissue damage; (ii) FGM performed at a very early age; and (iii) medicalisation of FGM.

There were significantly more referrals in 2013 and 2014, likely reflecting increased public and media awareness of FGM. Many cases came to light following a family dispute, school concerns and other medical or child protection concerns. Plans for holidays to country of origin, visits from elderly female relatives, a noticeable change in the child, spending longer in the toilet and missing school ${ }^{7}$ have all been suggested as warning signs in guidelines. To our knowledge, there is no evidence base for these indicators and none were present in our series.

It is important to note that FGM was confirmed in a child from Malaysia, emphasising the importance of remembering that this practice is not confined to African countries. There are no national estimates of prevalence in Malaysia or other countries in Southeast Asia and the Middle East, ${ }^{3}$ and so a high index of suspicion will help ensure cases are not missed.

In our series, the estimated year of FGM and ages of the children when performed are consistent with international data. A significant number of children $(15 \%)$ had undergone FGM when under 1 year of age which concurs with the global trend of FGM occurring at an increasingly younger age. ${ }^{3}$ This reduces the chance of the child remembering or being aware that the practice has taken place, thus reducing the chance of presentation and of a successful prosecution.

In this case series, $30 \%$ of the children reported symptoms that have been linked to FGM. However, most of these problems are relatively common in the paediatric population and seeking medical advice for these symptoms was often the reason that FGM came to light. Therefore, it is now essential to ask about FGM in the family history during a paediatric consultation in those presenting with genito-urinary symptoms or posttraumatic stress symptoms and also in child and adolescent mental health settings.

It is striking finding that many had FGM in a 'medical setting' or that it was performed by a person described as a 'doctor'.
Figure 5 Examination findings: female genital mutilation (FGM) by WHO classification.

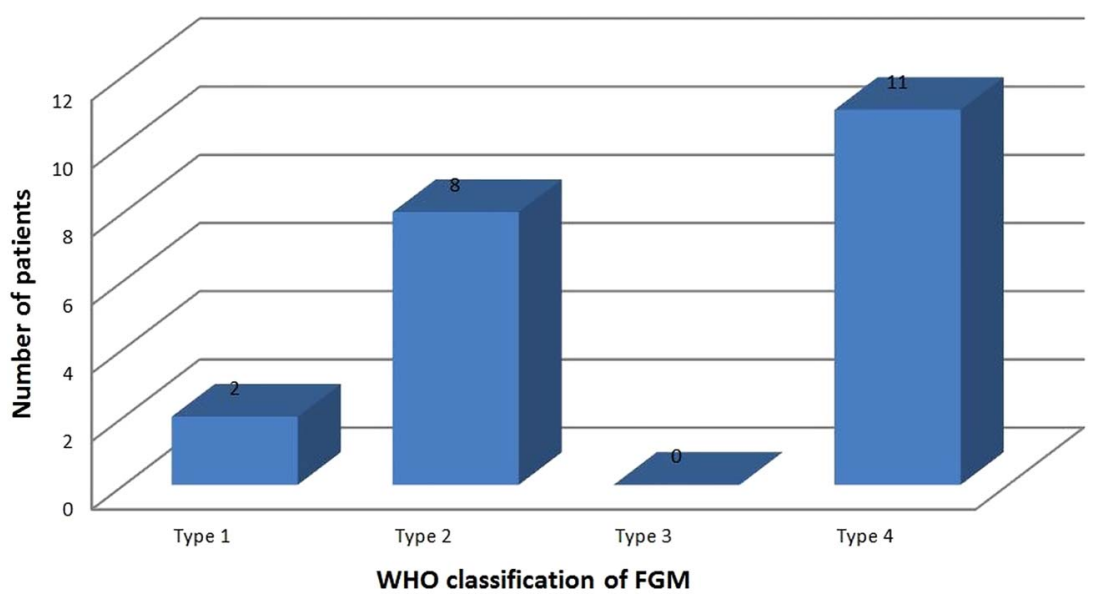


This trend towards increasing medicalisation of this practice in some communities is reported in international data, ${ }^{3}{ }^{4}$ but here it has occurred in a significantly higher proportion of cases, a trend which may be greater in migrant communities in the UK. The 'medicalisation' of FGM, although it reduces immediate medical risks, serves to legitimise and prolong the practice in some communities. ${ }^{3} 4$ The WHO issued a statement in 2010 condemning healthcare provider involvement in $\mathrm{FGM}^{9}$ and any suspicion of this occurring in the UK should be taken very seriously.

The majority of FGM seen in our series was WHO type 4, that is, the type with normal genital examination findings or a small genital scar. No child had WHO type 3 FGM (infibulation). Patients were examined by a consultant with many years of experience in child sexual abuse and genito-urinary problems. For clinicians with less experience and without specific paediatric experience, these subtle signs may be picked up even less frequently. Whatever the case, the history and findings must be documented and passed on to the police. A clinical judgement is necessary and should be framed in terms of the balance of probabilities, as with any child safeguarding concern.

It has been noted that within the WHO classification there is poor correlation between examination findings and self-reported type as well as a lack of clear distinction between the types on examination. ${ }^{10} 11$ The findings in this study were consistent with this. The WHO classification-while being more anatomically descriptive-was unhelpful both in describing the exact nature of examination findings and in discussing type of FGM with children and parents. It is more useful to place emphasis on thorough documentation of the physical findings and any description of the procedure rather than focusing on fitting the findings to the WHO classification. The inter-collegiate guidelines in the UK emphasise that FGM is child abuse and should be treated as such. ${ }^{12}$ This has the advantage that there already is an existing inter-agency framework and a professional duty to report. Guidelines also include the duty to assess the risk to siblings and other relatives. In contrast to child abuse, FGM carries particular challenges as it is a discreet act often perpetrated by relatives who believe they are acting in the best interests of the child. However, FGM is gender-based violence, which is often linked to forced and early marriage, ${ }^{13}$ and so tackling FGM in a social context requires professionals to have understanding of these wider issues.

The lack of prosecutions for FGM has been described as a national scandal. ${ }^{14}$ This case series highlights some of the barriers to prosecution. The Children's Act 1989 states that the child's welfare is paramount, ${ }^{15}$ and it may not be in her individual best interests to be asked to testify in court against her family. Proposed changes to the laws around FGM include mandatory reporting to the police of FGM in under 18-year-olds, FGM protection orders, and a positive duty of parents or carers to prevent a child being mutilated. These proposed changes may increase the chance of successful prosecutions.

\section{CONCLUSIONS AND RECOMMENDATIONS}

Although data on prevalence are sparse, there is a huge disparity between estimates of prevalence and the number of cases coming to light. This represents a failure to protect girls who are UK citizens and a largely hidden burden of safeguarding, medical and psychological problems in the paediatric population. ${ }^{16}$ The recent increase in referrals has led to the establishment of a dedicated multidisciplinary paediatric FGM clinic in our study centre with a paediatrician $(\mathrm{DH})$, paediatric gynaecologist (SC) and psychotherapist. The clinic provides sensitive medical care for children and includes accurate prospective data collection. If UK referrals rise, similar clinics may need to be established using this template.

In line with the international literature, this study identified the following trends: (i) FGM occurring at a younger age; (ii) increased prevalence of the less invasive types of FGM; and (iii) the medicalisation of FGM about which frontline professionals should be aware. The study highlights the limitations of the WHO classification of FGM in this setting and the authors would place emphasis instead on a thorough description of findings.

Contributors $\mathrm{DH}$ saw and examined all patients, collected data and wrote the paper; AA saw some patients, collected data and wrote the paper; KR saw some patients and collected data; SMC advised on the study, reviewed data and wrote the paper.

Competing interests None declared.

Provenance and peer review Not commissioned; externally peer reviewed.

\section{REFERENCES}

1 FORWARD. Raising voices of change. Annual report 2011/2012. 2012.

2 UN. The United Nations Convention on the Rights of the Child. The United Nations, 1989.

3 WHO. An update on WHO's work on female genital mutilation (FGM). Geneva: World Health Organisation, 2011.

4 UNICEF. Female genital mutilation/cutting: a statistical overview and exploration of the dynamics of change. 2013.

5 Macfarlane AD, Efua D. Female genital mutilation in England and Wales: updated statistical estimates of the numbers of affected women living in England and Wales and girls at risk. Interim report on provisional estimates. London: City University London, 2014.

6 Zaidi N, Khalil A, Roberts C, et al. Knowledge of female genital mutilation among healthcare professionals. J Obstet Gynaecol 2007;27:161-4.

7 HM Government. Multi-agency practice guidelines: female genital mutilation. London: The Home Office, 2014.

8 London Safeguarding Children Board. Safeguarding children at risk of abuse through female genital mutilation. London: 2009.

9 WHO. Global strategy to stop health-care providers from performing female genital mutilation. UNFPA, UNHCR, UNICEF, UNIFEM, WHO, FIGO, ICN, IOM, MWIA, WCPT, WMA. Geneva: World Health Organisation, 2010.

10 OHCHR, UNAIDS, UNDP, UNECA, UNESCO, UNFPA, UNHCR, UNICEF, UNIFEM, WHO. Eliminating female genital mutilation: an interagency statement. Geneva: World Health Organisation, 2008.

11 Elmusharaf S, Elhadi N, Almroth L. Reliability of self reported form of female genital mutilation and WHO classification: cross sectional study. BMJ 2006; 333:124.

12 RCM, RCN, RCOG, Equality Now, UNITE. Tackling FGM in the UK: intercollegiate recommendations for identifying, recording, and reporting. London: Royal College of Midwives, 2013.

13 Dorkenoo E, Elworthy S. Female genital mutilation. Hurst, 2006.

14 House of Commons Home Affairs Committee. Female genital mutilation: the case for a national action plan. Second Report of Session 2014-15. London: Home Office, 2014.

15 HM Government. Children Act 1989. 1989

16 Creighton SM, Hodes D. Female genital mutilation; what every paediatrician should know. Arch Dis Child 2016;101:267-71. 